\title{
Fratura dental com invasão de espaço biológico: Tratamento multidisciplinar
}

\author{
Dental fracture with invasion of biological space: Multidisciplinary treatment \\ Fractura dental con invasión del espacio biológico: Tratamiento multidisciplinar
}

Recebido: 13/04/2021 | Revisado: 25/04/2021 | Aceito: 27/04/2021 | Publicado: 11/05/2021

\author{
Bianca Joaquim do Nascimento \\ ORCID: https://orcid.org/0000-0001-5607-9174 \\ Universidade Estadual de Londrina, Brasil \\ E-mail: biancajoaquimm@gmail.com \\ Ana Julia Furlan da Silva \\ ORCID: https://orcid.org/0000-0002-4218-4771 \\ Universidade Estadual de Londrina, Brasil \\ E-mail: anajuliafurlan@icloud.com \\ Roberto Prescinotti \\ ORCID: https://orcid.org/0000-0001-7410-9517 \\ Universidade Estadual de Londrina, Brasil \\ E-mail: prescinotti@uel.br \\ Maria Beatriz Bergonse Pereira Pedriali \\ ORCID: https://orcid.org/0000-0001-8595-7108 \\ Universidade Estadual de Londrina, Brasil \\ E-mail: mbeatrizpedriali@uel.br \\ Amanda Vessoni Barbosa kasuya \\ ORCID: https://orcid.org/0000-0003-4401-9136 \\ Universidade Estadual de Londrina, Brasil \\ E-mail: amandakasuya@uel.br
}

\begin{abstract}
Resumo
Saúde periodontal e procedimentos restauradores estão intimamente relacionados e precisam estar em harmonia. O tratamento só apresenta bom prognóstico quando aspectos mecânicos, biológicos e estéticos são respeitados. $\mathrm{O}$ espaço biológico tem a função de proteger os tecidos de sustentação do elemento dental contra a agressão bacteriana e suas toxinas, sua preservação é fundamental para uma reabilitação adequada. Cirurgia periodontal envolvendo descolamento de um retalho total, osteotomia e osteoplastia são contraindicadas em alguns casos devido ao comprometimento da estética. Com isso, a extrusão ortodôntica combinada com fibrotomia é uma possibilidade de tratamento, principalmente quando envolvem a região anterior da maxila. O propósito desse trabalho é relatar e discutir um caso clínico com fratura coronorradicular dos incisivos superiores com invasão do espaço biológico. O caso teve uma atuação multidisciplinar e um planejamento de acordo com a condição socioeconômica do paciente, tendo em vista uma posterior reabilitação protética. Em um primeiro momento, realizou-se tratamento endodôntico, retenção intrarradicular com pinos de fibra de vidro e coroas provisórias. Posteriormente, a extrusão ortodôntica das raízes foi executada, com placa de acetato e elásticos ortodônticos, para restabelecimento do espaço biológico. Com planejamento adequado e realização da técnica correta foi possível proporcionar uma posterior reabilitação protética favorável e com bom prognóstico.
\end{abstract}

Palavras-chave: Extrusão ortodôntica; Espaço biológico; Reabilitação.

\begin{abstract}
Periodontal health and restorative procedures are closely related and need to be in harmony. The treatment only presents a good prognosis when mechanical, biological and esthetic aspects are respected. The biological space has the function of protecting the dental element support tissues against bacterial aggression and its toxins, and its preservation is essential for proper rehabilitation. Periodontal surgery involving detachment of a full flap, osteotomy and osteoplastic are contraindicated in some cases due to compromised esthetics. Thus, orthodontic extrusion combined with fibrotomy is a treatment possibility, especially when it involves the anterior region of the maxilla. The purpose of this article is to report and discuss a clinical case of an upper incisors coronoradicular fracture with invasion of the biological space. The case had a multidisciplinary approach and planning according to the patient's socioeconomic status, with a view to subsequent prosthetic rehabilitation. First, endodontic treatment was performed, intraradicular retention with fiberglass pins and temporary crowns. Subsequently, orthodontic root extrusion was performed using acetate plates and orthodontic elastics to re-establish the biological space. With adequate planning and performance of the correct technique it was possible to provide a subsequent favorable prosthetic rehabilitation with good prognosis.
\end{abstract}

Keywords: Orthodontic extrusion; Biological space; Rehabilitation. 


\begin{abstract}
Resumen
La salud periodontal y los procedimientos de restauración están estrechamente relacionados y deben estar en armonía. El tratamiento sólo presenta un buen pronóstico cuando se respetan los aspectos mecánicos, biológicos y estéticos. El espacio biológico tiene la función de proteger los tejidos de soporte del elemento dental contra la agresión bacteriana y sus toxinas, su preservación es esencial para una correcta rehabilitación. La cirugía periodontal que implica el desprendimiento de un colgajo completo, la osteotomía y la osteoplastia están contraindicadas en algunos casos debido al compromiso de la estética. Por lo tanto, la extrusión ortodoncia combinada con la fibrotomía es una posibilidad de tratamiento, especialmente cuando afectan a la región anterior del maxilar. El propósito de este estudio es informar y discutir un caso clínico con fractura coronorradicular de los incisivos superiores con invasión del espacio biológico. El caso contó con un enfoque multidisciplinar y una planificación acorde con la situación socioeconómica del paciente, con vistas a la posterior rehabilitación protésica. En un primer momento se realizó un tratamiento endodoncia, retención intrarradicular con pernos de fibra de vidrio y coronas provisionales. Posteriormente, se realizó una extrusión radicular ortodoncia utilizando placas de acetato y elásticos ortodoncias para restaurar el espacio biológico. Con una adecuada planificación y la realización de la técnica correcta fue posible proporcionar una rehabilitación protésica posterior favorable y con buen pronóstico.
\end{abstract}

Palabras clave: Extrusión ortodoncia; Espacio biológico; Rehabilitación.

\title{
1. Introdução
}

O sucesso do tratamento reabilitador na região ântero-superior do sorriso está pautado em dois pilares principais: estética vermelha (gengiva) e estética branca (dentes). Muitas vezes, mesmo com uma Odontologia multidisciplinar e técnicas cada vez mais avançadas e previsíveis, o restabelecimento do sorriso do ponto de vista biológico, estético e/ou funcional é bastante desafiador. Nesses casos, o diagnóstico e o planejamento são imprescindíveis para que, mesmo sabendo das limitações do caso, se atinja um resultado satisfatório que agrade tanto o paciente quanto o profissional (Cabral et al., 2017).

O conhecimento do efeito de cada trabalho restaurador sobre as estruturas periodontais e o cumprimento dos princípios biológicos é essencial para a longevidade dos procedimentos reabilitadores (Calicchio et al., 2016; Gunay et al., 2000). Adaptação das margens, contorno de restaurações, relação interproximal, lisura superficial e forças oclusais, possuem impacto biológico crítico sobre os tecidos periodontais (Tomar et al., 2013). Além disso, a preservação do espaço biológico é o que proporciona um adequado selamento em torno do elemento dental, agindo como uma barreira à penetração de microrganismos e seus produtos para os tecidos de suporte dentário (Gargiulo et al., 1961). Diante disso, o relacionamento das margens gengivais com a extensão dos preparos protético/restauradores tem sido objeto de pesquisa de vários autores, tendo em vista que as agressões ao periodonto de proteção podem causar danos irreparáveis e prejudiciais aos tecidos de sustentação do elemento dental (Gunay et al., 2000), uma vez que restaurações dentárias e saúde periodontal estão intimamente relacionadas.

O espaço biológico compreende a distância entre a base do sulco histológico e a crista óssea alveolar, apresentando uma dimensão média de 2,04 mm, que são distribuídas em 1,07 mm de inserção conjuntiva e 0.97 mm de epitélio juncional (Gargiulo et al., 1961). Cáries, restaurações subgengivais, reabsorções radiculares cervicais, perfurações iatrogênicas ou fraturas dentárias, podem provocar a invasão do espaço biológico. O tratamento odontológico, nessas situações clínicas, baseia-se em distanciar a área dentária comprometida dos espaços biológicos antes da execução do tratamento restaurador. Em determinadas situações a cirurgia periodontal envolvendo descolamento de um retalho total associado a osteotomia e osteoplastia está contraindicada por razões de proporção entre estética vermelha e branca, sendo a extrusão ortodôntica uma possibilidade. A extrusão ortodôntica, também conhecida como erupção forçada ou tracionamento vertical, é geralmente o procedimento de escolha na região anterior do arco dentário, e pode ser indicada em casos onde o comprimento radicular remanescente for maior que a altura da coroa protética a ser realizada (Normando et al., 2004; Teixeira et al., 2007).

Ao se realizar o tracionamento do dente no sentido oclusal, os tecidos periodontais, osso e gengiva inserida, tendem a acompanhar o movimento, aumentando desta forma a faixa de gengiva inserida e o nível da crista óssea do dente em questão. No decorrer do tratamento, portanto, é necessário após o período de contenção, realizar cirurgia periodontal para expor o 
remanescente radicular sadio e nivelar a topografia óssea e gengival (Janson et al., 2002). Quando o objetivo for expor somente remanescente radicular coronal à crista óssea, a realização de fibrotomia, que consiste na ressecção das fibras supra alveolares durante o tracionamento, pode evitar o acompanhamento dos tecidos de suporte, assim a necessidade de uma cirurgia periodontal após o período de contenção não será necessária. (Kozlowsky et al., 1988). Além disso, o aparelho ideal para a realização do tracionamento deve ser de fácil confecção e instalação, proporcionar um controle da magnitude e da direção da força e um baixo custo. $\mathrm{O}$ aparelho móvel é o mais indicado e de forma geral utilizam elásticos como dispositivo de geração de força (Normando et al., 2004).

Por fim, a reabilitação de um dente se conclui com a restauração da forma, função, estética e proteção do remanescente dentinário, possibilitando ao elemento dentário desenvolver seu papel no aparelho estomatognático. O sucesso dos trabalhos de prótese fixa está diretamente associado a um correto e criterioso planejamento, que deve ser executado de modo a atender às necessidades de cada paciente (Pegoraro et al., 2013; Ramalho et al., 2008). Durante a realização do preparo dental, deve ser seguido um protocolo criterioso, além da correta quantidade de desgaste, o preparo deve apresentar condições mecânicas de estabilidade e retenção para manter a prótese adaptada ao dente e ter longevidade (Farias et al., 2011).

As reabilitações protéticas sempre buscam a utilização de materiais que permitam a confecção de próteses satisfatórias, principalmente no que se refere à qualidade de ajuste, biocompatibilidade, resistência a manchamento e corrosão (Munoz-Chaves et al., 2002).

Assim para se obter êxito no tratamento reabilitador estético, este deve ser sustentado pela tríade estética, função e biologia. Cada um desses pontos deve ser cuidadosamente analisado durante a elaboração do planejamento, garantindo a previsibilidade e longevidade nos resultados do tratamento (Calicchio et al., 2016). Dentro desse contexto, o objetivo deste trabalho é demonstrar através de um relato de caso clínico a resolução de uma fratura dos incisivos superiores com invasão do espaço biológico. A resolução do caso foi baseada em uma abordagem multidisciplinar, pautada no planejamento detalhado e minucioso, possibilitando devolver saúde, função e estética com previsibilidade de resultados.

\section{Metodologia}

Refere-se a um relato de caso clínico (Pereira et al., 2018), visando a descrição detalhada das etapas clínicas de planejamento, tratamento e resolução de fraturas coronárias com invasão do espaço biológico, a fim de permitir a posterior reabilitação protética do caso. A autorização do procedimento e registro das imagens ocorreu mediante a assinatura do Termo de consentimento livre e esclarecido anexado no prontuário do paciente (8.384).

\section{Relato de Caso}

Paciente do gênero masculino, 66 anos de idade, compareceu à Clínica Odontológica Universitária da Universidade Estadual de Londrina, queixando- se de dor no dente 11, 21 e 22, após ter sofrido um trauma. No exame físico, observou-se a presença de uma fratura horizontal da porção coronária do dente 21 e mobilidade das coroas metalocerâmicas dos dentes $11 \mathrm{e}$ 22 (Figura.1). O exame radiográfico, confirmou a fratura do dente 21 com a invasão do espaço biológico, nos dentes 11 e 22 não foi possível a visualização da linha de fratura em virtude da presença dos núcleos metálicos (Figura.1). 
Figura 1: A) Aspecto clínico inicial da fratura no dente 21e próteses metalocerâmicas dos dentes 11 e 22 . B) Exame radiográfico mostrando fratura na região cervical.
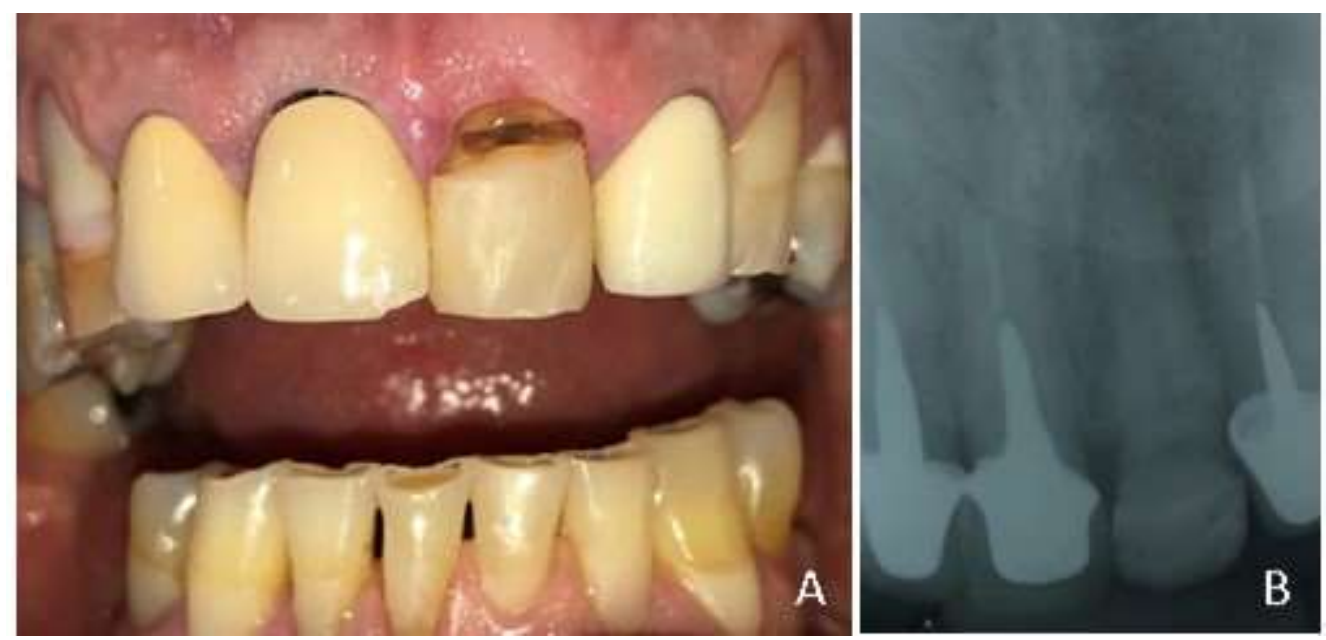

Fonte: Autores (2019).

Diante do relato de dor nos dentes 11 e 22, optou-se por remover as próteses fixas metalocerâmicas que apresentavam mobilidade grau 2 para investigação. A partir da remoção das próteses fixas observou-se a presença de uma fratura por palatino com invasão do espaço biológico e presença de inflamação gengival (Figura 2).

A partir da situação clínica, onde três incisivos superiores apresentavam-se fraturados e com invasão do espaço biológico, foram propostas as seguintes possibilidades de tratamento:

(1) Exodontia das raízes, instalação de implantes e confecção de novas próteses fixas implanto suportadas;

(2) Cirurgia de aumento de coroa e confecção de novas próteses fixas;

(3) Tracionamento ortodôntico e confecção de novas próteses fixas.

Após avaliação dos prós e contras de cada uma das opções, profissionais e paciente optaram pela realização do tracionamento ortodôntico dos três elementos e posteriormente a realização de próteses fixas.

Após a remoção dos fragmentos dentários dos três elementos fraturados, realizou-se a confecção de provisórios com dente de estoque e pino metálico pré-fabricado. Para garantir um adequado reembasamento da coroa provisória, uma gengivectomia foi realizada na porção palatina das raízes a fim de expor o término das fraturas (Figura 2). Na sequência, o tratamento endodôntico do dente 21 foi realizado, este sofreu necrose pulpar por rompimento do feixe vásculo nervoso. 
Figura 2: A) Remoção da prótese fixa do elemento 11 e do fragmento fraturado do dente 11. B) Vista vestibular. C) Vista oclusal mostrando o término subgengival das fraturas e inflamação gengival. D) Gengivectomia na palatina dos incisivos para expor o término cervical.
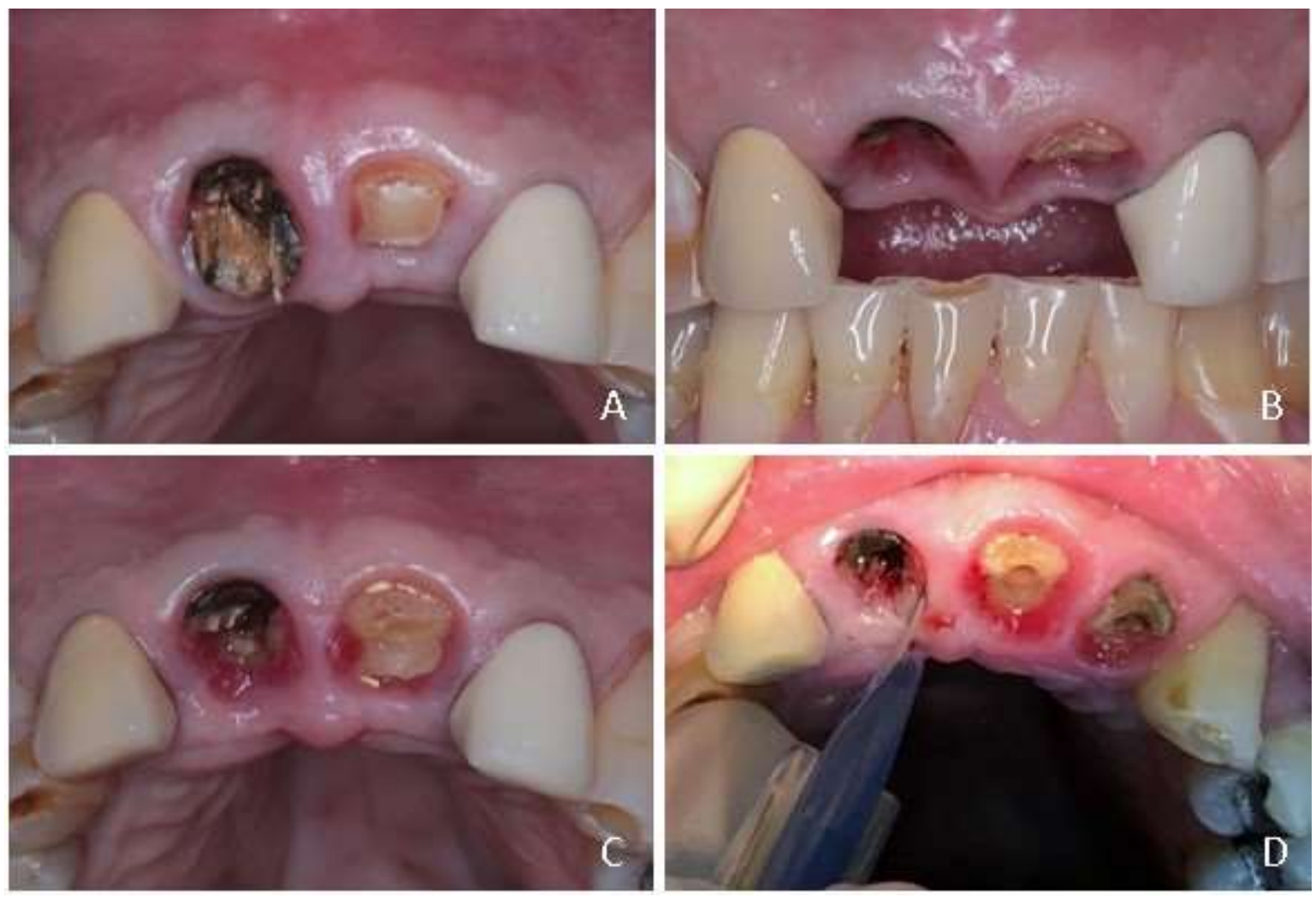

Fonte: Autores (2019).

Para realização do tracionamento, e em virtude de se tratar de uma região estética, optou-se pelo tracionamento através das coroas provisórias. Para isso, era essencial que os provisórios estivessem bem adaptados e retentivos às raízes dos elementos dentais, portanto, optou-se pela instalação de pino de fibra de vidro como retentor intrarradicular, em um comprimento radicular adequado. Entretanto, durante um período de paralização da Universidade, o paciente procurou atendimento privado de outro profissional, afim de cimentar o provisório do dente 11 que havia caído. Neste período, a instalação dos pinos de fibra de vidro ainda não havia sido realizada, e o mesmo ainda se encontrava confeccionado com pino metálico pré-fabricado. Ao retornar à clínica da UEL, o paciente não soube informar qual material de cimentação havia sido utilizado pelo dentista e a equipe não obteve êxito em remover o provisório, então, como a raiz já estava fragilizada pelo trauma, optou-se em manter o mesmo para a realização do tracionamento.

Nos dentes 21 e 22, deu-se continuidade ao planejamento inicial com a instalação dos pinos de fibra de vidro. Para isso, sob isolamento absoluto, foi feita a desobturação do conduto radicular, deixando apenas 4 mm de guta percha no terço apical, seleção do diâmetro do pino fibra de vidro através de radiografias e limpeza do conduto. Para cimentação do pino de fibra de vidro, a superfície do pino selecionado foi tratada com álcool 70\% e duas camadas de silano (FGM) e a cimentação foi executada com cimento resinoso autoadesivo (RelyX U200, 3M-ESPE). Na sequência, núcleos de preenchimento foram realizados em resina composta (Z350, 3M-ESPE). Para isso, a superfície dentinária foi tratada com ácido fosfórico a 37\% (DENTSPLY) por 15 segundos, aplicação do sistema adesivo (ADPER SINGLE BOND, 3M-ESPE) e fotoativação por 40 segundos. As coroas provisórias foram readaptadas posteriormente e cimentadas com cimento de ionômero de vidro (MAXXION, FGM) (Figura 3). 
Figura 3: Provisórios cimentados.

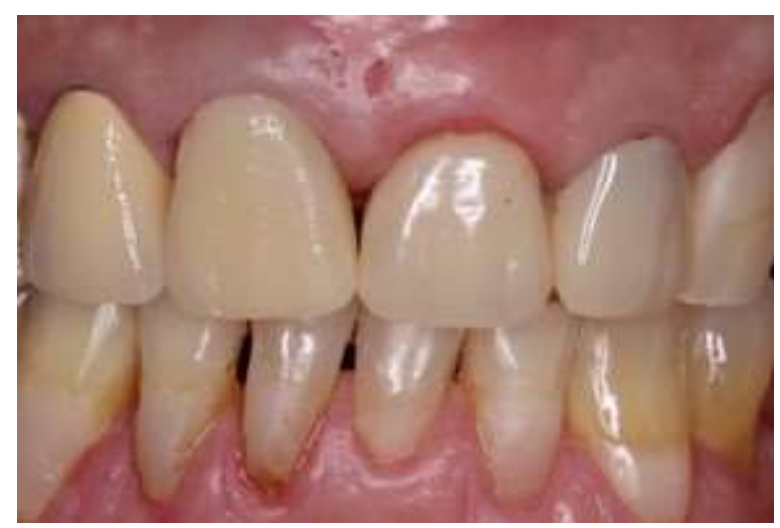

Fonte: Autores (2019).

A técnica de tracionamento utilizada foi a de movimentação rápida, pois os dentes em tratamento tinham o periodonto íntegro, com nível gengival e da crista óssea adequados em relação aos dentes adjacentes e havia necessidade de expor o remanescente radicular acima da crista óssea (Teixeira et al., 2007). Para realizar o tracionamento rápido dos dentes 11,21 e 22, confeccionou-se uma placa em acetato de $2,0 \mathrm{~mm}$ de espessura a partir de um modelo de gesso e realizada a colagem de um botão na face vestibular de cada provisório e outra na palatina da placa de acetato para cada dente (Figura 4A, B). A incisal do provisório foi desgastada a fim de criar um alívio entre provisório e placa, permitindo assim o tracionamento (Figura 4D). A fibrotomia foi realizada semanalmente com um gengivótomo de Orban para acelerar o processo e evitar o acompanhamento dos tecidos de suporte durante a movimentação (Figura 4 G, H).

O paciente foi orientado a envolver os botões das faces vestibular e palatina com elástico ortodôntico 1/8" de 3,2 mm de diâmetro, para promover força de extrusão vertical (Figura 4I, J). O uso do conjunto placa de acetato e elásticos ortodônticos foi realizado por 24 horas, retirando somente para as refeições e higienização. 
Research, Society and Development, v. 10, n. 5, e42010515003, 2021

(CC BY 4.0) | ISSN 2525-3409 | DOI: http://dx.doi.org/10.33448/rsd-v10i5.15003

Figura 4: A) Placa de acetato. B) Botões ortodônticos na face palatina. C) Faces vestibulares com os botões ortodônticos. D) Desgaste da incisal dos provisórios. E) Vista vestibular da placa instalada. F) Ajuste da placa. G) Fibrotomia na face vestibular. H) Fibrotomia na face palatina. I) Elásticos envolvendo os botões. J) Elásticos em posição, vista oclusal.
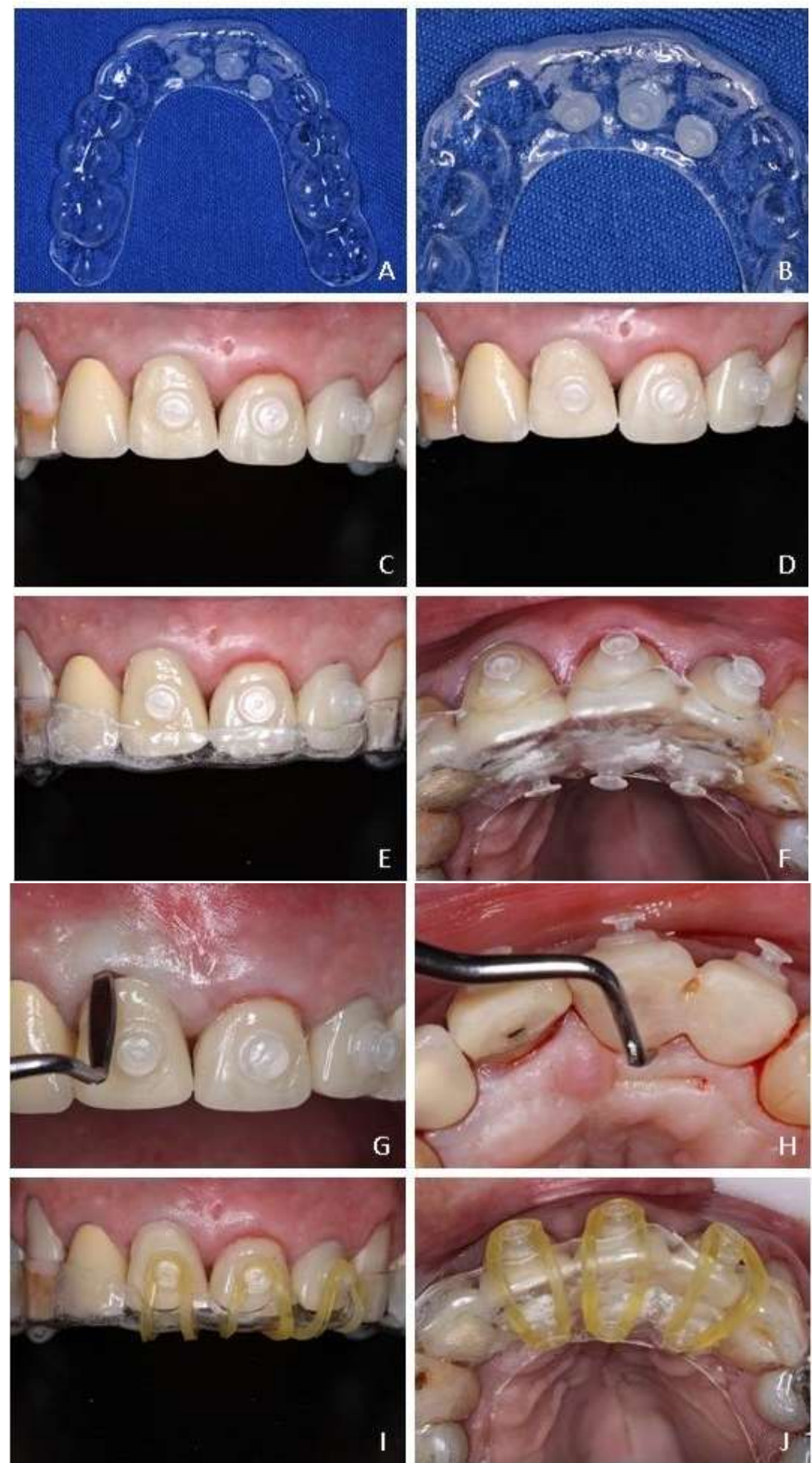

Fonte: Autores (2019). 
Research, Society and Development, v. 10, n. 5, e42010515003, 2021

(CC BY 4.0) | ISSN 2525-3409 | DOI: http://dx.doi.org/10.33448/rsd-v10i5.15003

Controles clínicos e radiográficos foram realizados semanalmente (Figura 5 e 6). Após 8 semanas, o tracionamento foi finalizado mediante a recuperação do espaço biológico e na sequência foi realizada contenção semi-rígida por 30 dias (Figura 5). Como os provisórios desgastados estavam comprometendo a estética do paciente, foi realizado o preparo dos términos cervicais e confecção de provisórios novos (Figura 5).

Figura 5: A) Aspecto clínico após 4 semanas de tracionamento. B) Aspecto clínico após 8 semanas de tracionamento.

C) Aspecto clínico após 8 semanas de tracionamento por palatino. D) Contenção ortodôntica semi -rígida. E) Provisórios após 3 meses. F) Palatina dos provisórios após 3 meses.
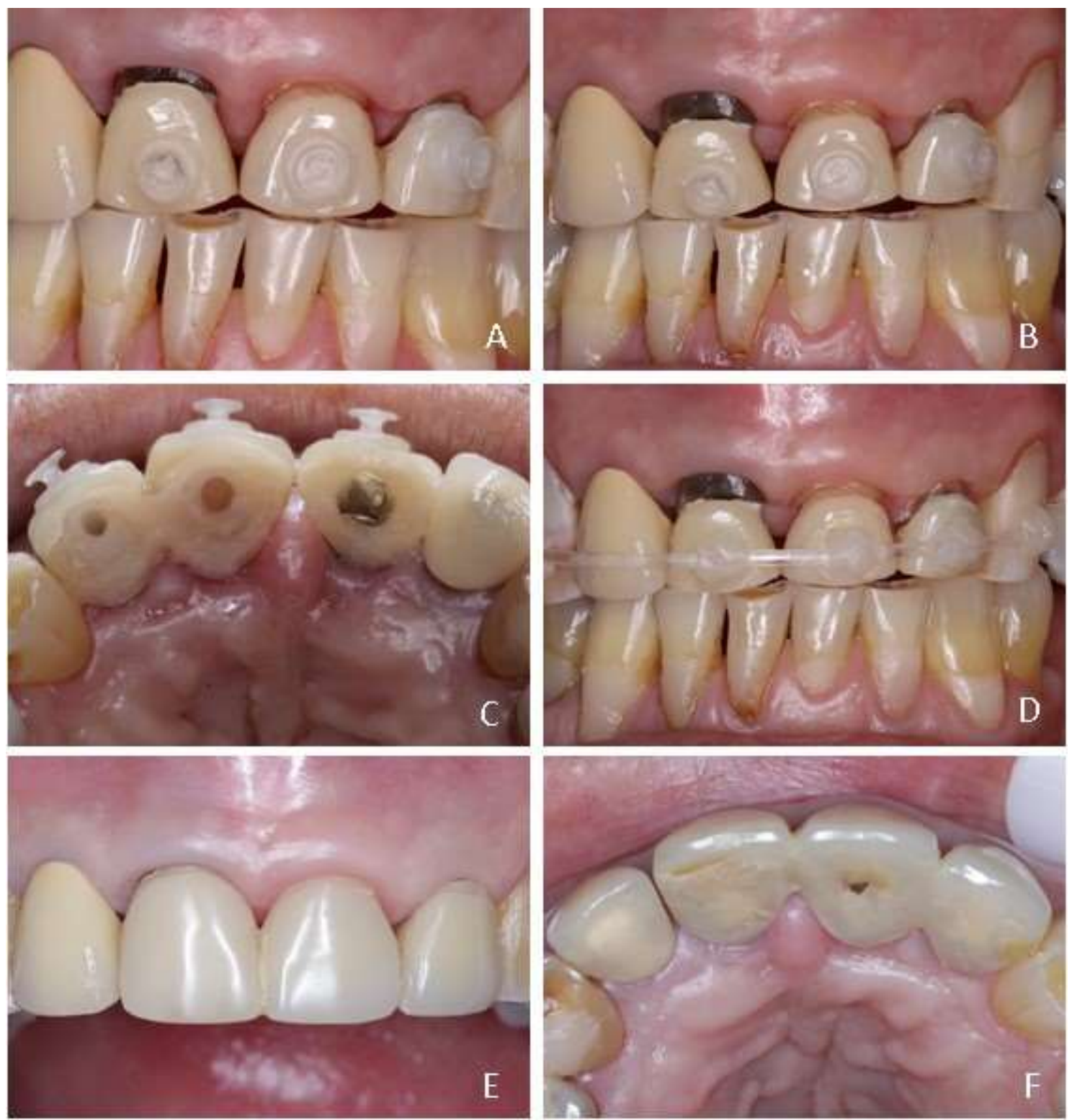

Fonte: Autores (2019 e 2020). 
Figura 6: A) Controle radiográfico dos dentes 11e 21. B) Controle radiográfico do dente 22.
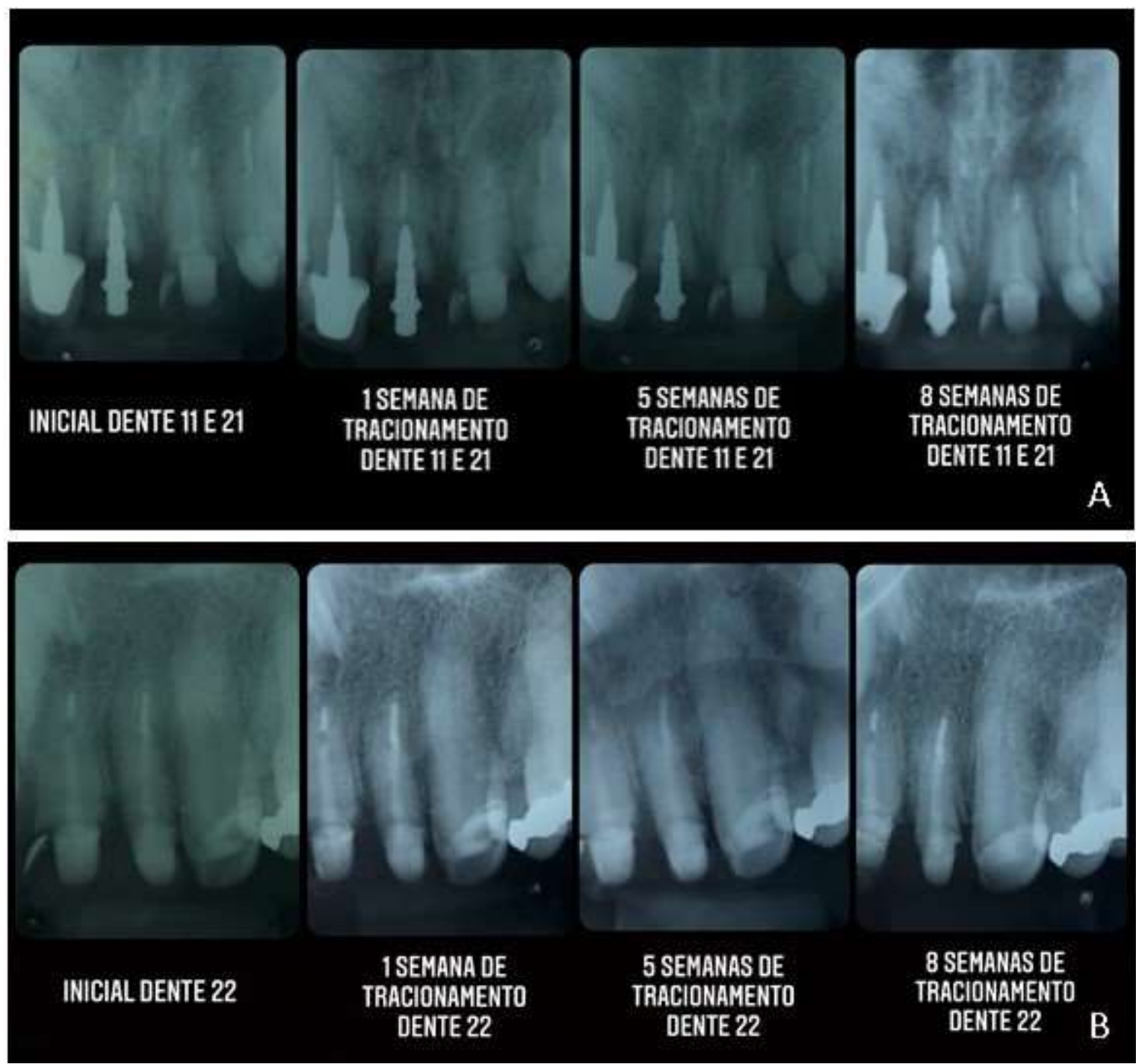

Fonte: Autores (2019 e 2020).

\section{Resultados e Discussão}

Atualmente, é muito frequente a procura de casos em que seja necessária uma reabilitação multiprofissional, que pode incluir endodontia de emergência ou tratamento periodontal para manutenção das estruturas dentárias e periodontais, associado à reabilitação morfológica, funcional e estética dos elementos dentais. O tratamento multidisciplinar não só oferece a oportunidade de mudar a abordagem odontológica, mas também de desenvolver e moldar a aparência ou a imagem de um indivíduo e, ao mesmo tempo, fornecer restaurações funcionais, duráveis, estéticas e saudáveis (Mendoza et al., 2012).

Nesse relato de caso apresentamos uma situação clínica com fraturas horizontais na região da junção amelocementária, que resultaram na invasão do espaço biológico nos dentes 11, 21 e 22. Ao considerarmos as possibilidades e opções de tratamento, além da condição socioeconômica do paciente, o presente caso poderia ser resolvido através da instalação de implantes ou de uma prótese parcial removível. Entretanto, após um minucioso planejamento, verificou-se a possibilidade da restauração dos elementos fraturados através de próteses fixas, tornando-se obrigatório para essa conduta o restabelecimento dos espaços biológicos. Para que a opção de tratamento escolhida fosse possível, foi necessária uma combinação multidisciplinar de terapia ortodôntica, endodôntica, periodontal e protética (Clark \& Levin, 2019). 
Todas as opções de tratamento foram apresentadas ao paciente, bem como suas limitações, e o mesmo optou pela realização do tracionamento ortodôntico em conjunto com a equipe multiprofissional. O paciente apresentava uma linha do sorriso alta e uma prótese fixa no dente 12 em perfeitas condições, contraindicando um aumento de coroa clínica convencional pois causaria desarmonia no arco gengival, trazendo prejuízos estéticos ao paciente com a exposição do término da coroa metalocerâmica e sua consequente necessidade de substituição, encarecendo o tratamento e tornando-o inviável ao paciente, em virtude da sua condição socioeconômica. As vantagens do tracionamento ortodôntico também foram levadas em consideração durante o plano de tratamento. A técnica, quando bem indicada, proporciona um efeito estético mais favorável do que a cirurgia de aumento de coroa clínica, não impondo um sacrifício ósseo pela redução de suporte alveolar em dentes adjacentes não comprometidos e uma deformidade estética pelo aumento na proporção coroa/raiz (Martos et al., 2014; Silva et al., 2020).

Além dos fatores já descritos, no presente caso relatado, os dentes envolvidos no tratamento apresentavam periodonto íntegro, ou seja, níveis gengivais e crista óssea adequados em relação aos dentes adjacentes, sendo necessária apenas a exposição do remanescente radicular sadio acima da crista óssea. Portanto, visando a restauração das distâncias biológicas, foi recomendado proceder com o tracionamento rápido associado à fibrotomia, evitando assim, irritações aos tecidos moles ou futuras intervenções cirúrgicas no tecido gengival (Janson et al., 2002; Romanelli, 2014).

A reabilitação estética e funcional de dentes tratados endodonticamente, com perda de grande quantidade de estrutura coronária, requer na maioria das vezes utilização de retentores intrarradiculares como forma adicional de estabilizar e reter o material restaurador (Reis et al., 2010). No presente caso, um ponto relevante na escolha do retentor intrarradicular foi o tracionamento ortodôntico, que seria realizado através das coroas provisórias, exigindo uma boa adaptação e retenção destas às raízes dos elementos dentais. Dessa forma, o pino de fibra de vidro foi o material de escolha, pois além de fornecer a ancoragem das coroas provisórias durante o tracionamento ortodôntico, faria parte da restauração definitiva em virtude das suas propriedades mecânicas próximas à dentina radicular e possibilidade de adesão ao remanescente dentinário. No caso relatado, não houve necessidade da reanatomização dos pinos de fibra de vidro, pois os condutos radiculares dos dentes estavam atresiados e os pinos pré-fabricados ficaram justapostos às paredes dos canais.

Os pinos de fibra de vidro apresentam como vantagem o fato de possuírem características físicas e mecânicas mais próximas da estrutura dental do que os pinos metálicos e possuem uma cimentação adesiva. Tais características os tornam capazes de resistir aos impactos mastigatórios sem se deslocar ou provocar o efeito de cunha na raiz (Goyatá et al., 2008). Estudos mostram que o pino de fibra de vidro em dentes tratados endodonticamente com dano coronário grave apresenta taxas de sobrevida global de 3 a 7 anos mais altas em comparação com pinos metálicos (Wang et al., 2019; Cloet et al., 2017). Geralmente, as fraturas radiculares são mais desfavoráveis com pinos metálicos, uma vez que os potenciais locais de fratura são mais apicais, enquanto os pinos de fibra de vidro, mais cervicais. (Figueiredo et al., 2015).

Dependendo da condição clínica encontrada, vários métodos de extrusão são viáveis. Como o tratamento ocorreu em clínica de graduação, o uso de aparelho fixo ficou inviável, então o tracionamento foi realizado com uso de forças elásticas, através de uma placa de acetato com botões ortodônticos. Nessa etapa, é fundamental a colaboração do paciente quanto ao uso contínuo da placa e troca dos elásticos para se obter o resultado esperado. Em todo o período de tracionamento foi realizado o acompanhamento radiográfico, a fim de verificar se a extrusão estava ocorrendo conforme o previsto e evitar possíveis intercorrências. Outro fator determinante durante o tratamento foi a realização da fibrotomia supra óssea, que consiste em uma incisão circunferencial intra- sulcular realizada com intervalos de 7 a 10 dias, evitando o acompanhamento dos tecidos de suporte e a necessidade de uma cirurgia periodontal posteriormente (Pontoriero et al., 1987). Considerando também a possibilidade de uma recidiva da extrusão obtida, foi realizado um período de contenção do dente após a fase ativa, pois esse deve permanecer imóvel na posição alcançada no final da extrusão, havendo reorganização das fibras do ligamento e também 
neoformação óssea na região apical (Janson et al., 2002). A técnica de extrusão ortodôntica, quando bem indicada, proporciona resultados estéticos e funcionais favoráveis, pois evita complicações presentes na cirurgia de aumento de coroa clínica, como recessão gengival, mudança do contorno gengival, possível perda de papila interdental e proporção coroa - raiz desfavorável (Goenka et al., 2011; Santos et al., 2020). Com um planejamento multidisciplinar adequado, através do tratamento endodôntico, retentores intrarradiculares e provisórios, foi possível realizar o tracionamento e o restabelecimento do espaço biológico dos três dentes, para posterior reabilitação com próteses fixas, aumentando assim a longevidade das mesmas. Devido a pandemia da Covid-19 e a consequente impossibilidade de atendimentos na clínica de graduação da Universidade, o tratamento teve que ser interrompido (Odeh et al., 2020). O paciente optou em continuar com o planejamento proposto no início do tratamento e está aguardando o retorno das atividades para a sua finalização.

\section{Conclusão}

A extrusão ortodôntica é uma técnica amplamente utilizada em clínica, principalmente em áreas estéticas, pois permite o restabelecimento do espaço biológico e preserva a harmonia do tecido gengival. A opção pela placa de acetato e elásticos ortodônticos é uma alternativa de fácil execução e baixo custo, podendo ser empregada pelo clínico geral com facilidade, além disso, quando bem indicada e planejada, possui um excelente prognóstico. Mais estudos devem ser realizados de forma controlada e randomizada para verificar o benefício da técnica de tracionamento utilizada no presente caso, bem como comparar o tempo de tratamento, custo e eficácia com outras metodologias já consolidadas na literatura.

\section{Referências}

Cabral, F., Serra, M., Santos, F.M.L., Luis, C., Kyrillos, M., Moreira, M., et al. (2017) Como alcançar resultados satisfatórios frente a uma limitação biológica? A interface entre as especialidades para a melhor solução clínica. J Clin Dent Res, 14(3), 42-58.

Calicchio, L., Kyrillos, M., Moreira, M., Giordani, G., Cabral, F., Nhoncance, W., et al. (2016) Odontologia minimamente invasiva aplicada na transformação estética do sorriso. J Clin Den Res, 13(4), 53-64.

Clark, D., \& Levin, L. (2019). In the dental implant era, why do we still bother saving teeth? Dental traumatology: official publication of International Association for Dental Traumatology, 35(6), 368-375.

Cloet, E., Debels, E., \& Naert, I. (2017) Controlled Clinical Trial on the Outcome of Glass Fiber Composite Cores Versus Wrou ght Posts and Cast Cores for the Restoration of Endodontically Treated Teeth: A 5-Year Follow-up Study. Int J Prosthodont, 30(1), 71-79.

Farias, F. A. R., Feltrin, P. P., Zanetti, A. L. E., \& Inoue, R. T. (2011) Preparo dentário para coroa metalocerâmica em dentes anteriores, por meio da técnica de referência Inoue \& Zanetti. $R G O$, 59(1) 81-88.

Figueiredo, F. E. D., Martins F. P. R. S., \& Faria S. A. L. (2015) Do Metal Post-retained Restorations Result in More Root Fractures than Fiber Post-retained Restorations? A Systematic Review and Meta-analysis. Journal of Endodontics, 41(3), 309-316.

Gargiulo, A.W., Wentz, F.M., \& Orban, B. (1961) Dimensions and relations of the dentogingival junctions in humans. J Periodontol ,32, 261-97.

Goenka, P., Marwah, N., \& Dutta, S. (2011) A multidisciplinary approach to the management of a subgingivally fractured tooth: a clinical report. $J$ Prosthodont, 20(3):218-223.

Goyatá, F.R., Thomé, E.M.O.S., Brum, S.C., Oliveira, R.S., \& Ferreira, T.F.R.Z. (2008) Multidisciplinary restoration treatment - a clinical report. Int J Dent, Recife, 7 (2),142-146.

Gunay, H., Seeger, A., Tschernitschek, H., \& Geurtsen W. (2000) Placement of the preparation line and periodontal health--a prospective 2-year clinical study. Int J Periodontics Restorative Dent, 20 (2),171-81.

Janson, M.R.P., Passanezi E., Jason, R.R.P., \& Pinzan, A. (2002) Tratamento Interdisciplinar II - Estética e distância biológica: Alternativas ortodônticas para remodelamento vertical do periodonto. R Dental Press Ortodon Ortop Facial, 7(4), 85-105.

Kozlovsky, A., Tal, H., \& Lieberman, M. (1988) Forced Eruption Combined with gingival fiberotomy: A technique for clinial crown lengthening. J Clin Periodontol, 15, 534-538.

Martos, J., Silveira, L. F. M., Baldisserra, R.A., \& Cruz, L. E. R. N. (2014) Extrusão ortodôntica e realinhamento do espaço biológico em pré-molar com fratura subgengival. Revista Odontológica do Brasil Central,23(67),212-216.

Mendoza R.S., Szalay, E. R., Treviño, A.S., \& Olivares, S. T. (2012). Multi-disciplinary prosthetic rehabilitation: Clinical case report. Revista odontológica mexicana, 16(2), 112-122. 
Research, Society and Development, v. 10, n. 5, e42010515003, 2021

(CC BY 4.0) | ISSN 2525-3409 | DOI: http://dx.doi.org/10.33448/rsd-v10i5.15003

Munõz-Chaves, O. F., Lombardo, G. H. L., Terence, R. L., \& Araújo, P. C. A. (2002) Prótese fixa metalocerâmica com liga de titânio comercialmente pura. Revista Brasileira de Prótese Clínica e Laboratorial, 4(19), 196-201.

Normando, A.D.C., Simone, J.L., Soares, M.S., \& Tortamano N. (2004) A extrusão ortodôntica como recurso no tratamento das invasões dos espaços biológicos periodontais - indicação clínica e divulgação de um método simplificado de tratamento. J Bras Ortodon Ortop Facial, 9(53), 502-10.

Odeh, N. D., Babkair, H., Abu-Hammad, S., Borzangy, S., Abu-Hammad, A., \& Abu-Hammad, O. (2020). COVID-19: Present and Future Challenges for Dental Practice. International journal of environmental research and public health, 17(9), 3151.

Pegoraro, L. F., Araújo, C. dos R. P., Bonfante, G., \& Conti, P. C. R. (2013). Prótese fixa: bases para o planejamento em reabilitação oral. São Paulo: Artes Médicas.

Pontoriero, R., Celenza F, Jr., Ricci, G., \& Carnevale, G. (1987) Rapid extrusion with fiber resection: a combined orthodontic-periodontic treatment modality. Int J Periodontics Restorative Dent, 7(5):30-43.

Ramalho, A. C.D., Mariz, A. L., Beatrice, L.C.S., Silva, C. H.V., \& Filho, P.V.M. (2008) Estudo comparativo da resistência radicular à fratura em função do comprimento e da composição do pino. $R F O, 13(3), 42-46$.

Reis, B. R., Soares, P. B. F., Castro, C.G,. Santos Filho P.C. F., Soares, P. V., \& Soares, C.J.(2010) All ceramic crown associated to fiberglass post: a clinical case report. Robrac, 19(50).

Romanelli J. (2014) Reabilitações estéticas gengivais compostas pela extrusão ortodôntica. Rev Dental Press Estét, 11(1):46-59.

Santos Silva, M. D., Vitório de Farias Sá, A. K., Mello Figueiredo, L., \& D’Almeida Borges, C. (2020). Extrusão ortodôntica de dentes traumatizados: revisão integrativa da literatura. Caderno De Graduação - Ciências Biológicas E Da Saúde - UNIT, 6(2), 50.

Silva, A. B. R., Alves, H., Lazarino, V. L., Nascimento, Y. M. L. do., Castello, L. F. M., Costa, A. M. C., Oliveira, T. T. C. de., Pingarilho, L., Santos, T. de S., \& Macedo, I. de A. B. (2020). Minimally invasive surgical techniques in clinical crown lengthening: A systematic review. Research, Society and Development, $9(10)$, e579108256.

Teixeira, R. O., Falabella, M. E.V., Falabella, J.M., Teixeira, H.G.C., \& Calvário, M. A.F. (2007) Tracionamento dentário com finalidade periodontal: relato de caso. $R G O, 55(4), 404-411$.

Tomar, N., Bansal,T., Bhandari, M., \& Sharma, A. (2013) The perio-esthetic-restorative approach for anterior rehabilitation. J Indian Soc Periodontol, 17(4), $535-538$.

Wang, X., Shu, X., Zhang, Y., Yang, B., Jian, Y., \& Zhao, K. (2019) Evaluation of fiber posts vs metal posts for restoring severely damaged endodontically treated teeth: a systematic review and meta-analysis. Quintessence Int, 50(1):8-20. 